\title{
Analysis on Contemporary Chinese Tourism Performing Arts Market
}

\author{
Shu $\mathrm{Li}^{1,{ }^{*}} \mathrm{Hao} \mathrm{Liu}{ }^{2}$ \\ ${ }^{1}$ Film and Television Department, China-ASEAN Art College of Chengdu University, Chengdu, Sichuan, China \\ ${ }^{2}$ Academic Administration Department of Chengdu University, Chengdu, Sichuan, China \\ *Corresponding author. Email: lishu@cdu.edu.cn
}

\begin{abstract}
In the broad perspective of mass media culture research, music and cultural creation, film and television, animation and games, online education, drama, art museum and so on are all important concerns of the cultural industry, while tourism performance is rarely written in the cultural industry report or has been neglected in the art creation, which does not match with the rapid development of tourism performance. From the perspective of media culture research, this paper analyzes the walking landscape, gazing carnival, boiling market and neglected pan art creation in the current tourism performance, aiming at calling for more attention to the huge cultural potential of tourism performance, promoting in-depth exchanges between the industry and academia, and contributing to the promotion of national cultural soft power.
\end{abstract}

Keywords: Walking landscape, Gazing carnival, Media culture, Tourism performance.

\section{INTRODUCTION}

Since the year 2000, through the development of the national economy and the enhancement of cultural demand, the culture and tourism industry have increasingly become people's consumption routine. In March 2018, the Ministry of Culture and Tourism of the People's Republic of China had been approved its establishment. It is not difficult to read the positive signals of the integration of culture and tourism.

The "2017-2018 China Tourism Performing Arts Development Research Report"[1] pointed out that the consumer group of the tourism performing arts industry has increased by $27 \%$ in the past year, and the box office has increased by $20 \%$ to 5.1 billion RMB, which is faster than the box office of Chinese movies. Definitely, "tourism is a highly industrialized and urbanized product of modern society." Tourism performing arts create a dazzling "walking landscape" and "gazing carnival". As the art historian Robert Hughes said: "We are different from our ancestors. We live in a world we make

*Fund: This paper was supported by $\mathrm{Su}$ Video Studio and major scientific research projects, School of Film, Television and Animation, China-ASEAN Art of College of Chengdu University ourselves ... 'Nature' has been replaced by a culture of congestion. Here we mean cities and Congestion of mass propaganda tools. "With the rise of the mass media, the explosion of information and excess of visual consumption have spawned new artificial landscapes and attention economies.

Throughout the development of tourism performing arts, from the "Splendid China (Jin Xiu Zhong Hua)" Folk Village in Shenzhen in the 1980s to the "Window of the World (Shi Jie Zhi Chuang)" theme park in the 1990s, the elderly jazz performances at the Shanghai Peace Hotel, Xi'an Tangle Palace's "imitation Tang music dance" to Lijiang's "Naxi ancient music", the concept of tourism performing arts has actually entered the homes of ordinary people in China. Entering the 21st new century, CCTV's brand Mid-Autumn Festival created a precedent of "Chinese love"-a holographic landscape evening gala, and promoted the vigorous development of tourism and cultural industries in second and third tier cities. Subsequently, "Impression", "Landscape", and "Eternal Love" series of large-scale real-life tourism performances, local characteristics and technological sense of theatrical theatre performances, intangible cultural heritage tourism 
performances, red tourism performances and other flowers bloom everywhere in mainland China.

According to incomplete statistics, there are about 300 tourist performances in the country, but $80 \%$ of them are in a state of change, and a few are profitable. The "two-eight law" derived from management is also applicable to the cultural tourism performance market. How to break a single "ticket economy"? Is there any approach to break through the embarrassing situation of the audience's low recognition of cultural tourism performances? What is the method to meet people's growing material and cultural needs and the need for a better life? In order to follow the development of society and the trend of the times, the First Session of the Thirteenth Chinese National People's Congress passed a decision on the reform plan of the State Council, approved the establishment of the Ministry of Culture and Tourism of the People's Republic of China, and no longer retained the Ministry of Culture and National Tourism Administration. In March 2018, the Ministry of Culture and Tourism of the People's Republic of China was approved to be established. In January 2019, at the meeting of directors of the National Department of Culture and Tourism, it was proposed to promote traditional non-heritage projects such as traditional skills and performing arts into key tourist attractions and tourist resorts, and promote red tourism, tourism performing arts, cultural heritage tourism, theme parks, Cultural theme hotels and other integrated development formats have been upgraded. A series of positive policy signals indicate that the current development trend of China's tourism performances, but its performance model, business model, management model, etc. have not been updated for a long time and are facing serious challenges. The vigorous development of tourism performing arts has brought a wider space for the personal experience of walking. The most prominent feature is the creation and invention of virtual landscapes represented by theme parks and film and television cities, and carnival of collective gaze brought by mobile tourists. As a complex social activity, the performing arts of tourism, under the multiple demands of the consumer market and cultural aesthetics, have gradually reflected a pan-artistic cross-border tendency.

\section{WALKING LANDSCAPE: SPIRITUAL EXPERIENCE AND PHYSICAL LIBERATION}

As one Chinese ancient said, to be a wealthy man needs reading thousands of books as well as walking thousands of miles. Coincidentally, today people still believe in "either read or travel, there is always a body and soul on the road." Especially in the past 40 years since China's reform and opening up, the tourism demand and consumption of Chinese people have been increasing year by year. Needless to say, tourism is no longer considered a luxury or unnecessary product for the rich, and people's call for "the world is so big, I want to see it" have been regarded as a new right and lifestyle. In fact, teenagers who participate in summer camps, winter camps, graduation trips or study abroad, brides and grooms who choose to travel to get married or honeymoon, friends take annual leave only for meeting on the island, retired seniors backpacking to embracing the second spring... For more and more people, "on the road" has become the norm in their lives. Before dying, it is estimated that no one will say "I should spend more time in the office", on the contrary, people are likely to say "I should go out and walk around and see the world." The famous British sociologist John Urry first published his pioneering monograph "The Tourist Gaze" in 1990, he mentioned that:

Visitors focus on the features of the landscape and the urban landscape that distinguish them from that everyday experiences. His "gazing on destination image", "tourist experience" and other tourism gaze theories in today's era of globalized media still have guiding significance for interpreting tourism and cultural tourism performances. The "cultural industry" wrapped in modern mass media gave birth to the "Society of spectacle". The alienation shaped pseudoindividualism of people from the cultural industry criticized by Theodor Adorno from German Frankfurt school, to the modern production criticized by Guy Debord, the ubiquitous accumulation of spectacles brought about, the collective unconscious desires and desires of human beings were "used and satisfied" in the spectacle disorder. I have to admit that tourism performance is filling people's dissatisfaction with ordinary life with its increasingly active attitude.

Looking back on the current development of domestic tourism performing arts, audiences who are accustomed to visual spectacles gradually appreciate the landscape and single gaze of 
landscapes, gradually shifting to the interactive needs of human landscapes. "I'm here, I've seen it, I've conquered it" is no longer the declaration of victory of the emperor's prime minister, it has become a subtext of the new era traveler's "checkin". From the "gaze" theory of French philosopher Michel Foucault, pointing out the power relations and subject matter behind gaze, to the "tourism gaze" theory of the British scholar John Urry, promoting the audience's potential psychology for tourism and their inner pursuit of alien life, the process of walking and walking, the role of seeing and being watched being transformed, and the power relationship between subject and object to start a game.[2] In particular, the new generation of new human beings, the younger generation's understanding of "romantic" may no longer be a letter over a long period of time or a life span, but rather the pleasure of holding hands and traveling around the world.

Tourism performances have sprung up these couple of years. Visitors who choose to leave and "on the road" are gradually turning their "gaze" on the outside world to "inspection" on the inner world. It is not just the human body that walks, but the landscape that moves in front of the eyes. Tourism performing arts provides a "walk-in" visual carnival beyond the mass media. In a sense, tourism performing arts is a 'walking landscape'. It is similar to and different from the audiovisual 'landscapes' created in postmodern movies, idol reality shows, and commercials. It also has assimilation and compilation of refined and popular culture. However, in the natural and man-made landscapes in walking, tourism performances have greatly liberated people's bodies, and provided new gaze objects - interpersonal relationships and selfreflection in addition to landscape paintings and "people, mountains and sea" scenery.

\section{FILMS BOILING MARKET: PERCEPTUAL CONSUMPTION AND ECOLOGICAL CHAOS}

On the one hand, watching or experiencing travel performances has become the "dinner" of tourism and the "standard configuration" on the road. On the other hand, the sensibility and blindness of cross-border consumption have fewer repeat customers or low reputation, arousing less profits and losses. The single ticket economy, homogeneous "impression", "landscape" and "eternal love" performance content, grouped season arrangements, false satisfaction of grand song and dance narrative, etc. are also the ecological chaos exposed in the boiling market of tourism. Performance, profit, development and governance models need to be upgraded and updated. The reform of national institutions has combined the two major departments of culture and tourism. How to find the balance of cultural tourism, economics, and artistic creation in the global pattern of "Internet+", export cultural confidence, and obtain lasting vitality, which is the uttermost solving problem of current tourism performing arts.

John Urry described the development of mass tourism as the death of tourism in his book "The Tourists Gaze". When tourism became "tourist culture", similar to Adorno's criticism of "cultural industry", mass tourism made everything becomes entertaining, sensory and consumed. The cultural industry "provides standard products to meet the same needs in countless places." Mass tourism, as an obvious symbol of tourism culture, was once a characteristic of tourism democratization and standardization. Today's travellers who are looking for another way are seeking personalized and tasteful personal customization has created a new cultural elite who pursue a true, aesthetic, and even ascetic unique tourism culture. In addition, many emerging options of ours in tourism and leisure aspect are wrapping us with a full range of packages that are driving new transportation, accommodation, catering, entertainment, retail, health and wellness, photography, entertainment, culture and art, electronics, and other brand new industry. Tourism has become the world's largest industry, worth trillions of dollars, far exceeding world military spending.

According to the "2017-2018 China Tourism Performing Arts Industry Research Report", in the past year, China's tourist performance audience reached 68.212 million, the tourist performing arts consumer group increased by $26.5 \%$, and the box office increased by nearly $20 \%$ to 5.146 billion RMB, which created a new high in history. The report takes stock of the boiling cultural tourism market in terms of theatrical performances, performances, audiences, and needs. It also points out that, benefiting from China's economic transformation and consumption upgrading, the demand for tourism content by tourists has been increasing. The transformation of tourism into a 'tourism + ' and 'experience + ' cultural model has promoted a significant increase in tourism performing arts. The report also mentioned that the theme park tourism performance is developing strongly, contributing $45.3 \%$ of the box office with 
$9.6 \%$ revenue. There are 171 theatre performances, accounting for $62.9 \%$ of the total, and the box office revenue is only $26.4 \%$. The 'two-eight law' of the tourism performing arts market, which does not combine tourism performances with scenic spots, is a more prominent problem in the current market disorder.

In recent years, the performances of opera, song and dance, acrobatics, folk customs and drama narratives represented by "ERA-Time and Space" and "Seeing Pingyao" have been mixed. Relying on the background of tourist attractions, combined with the actual performance of local culture, and the theme park or theme theatre performance of the complex tourism complex such as "Changlong Circus" and "Eternal Love" series are the three main types of tourism performing arts. However, whether it is a super-large show with thousands of people or a small theatre with hundreds of people, looking at domestic tourism performances, even if invited to tour abroad, it is difficult to find true copyright protection for cultural IP. If we compare the Wanda theme parks in China and the American Disney theme park in Shanghai, it is not difficult to see the difference. Although the former blossoms everywhere, it lacks international vision and cultural vitality, and its profit model is relatively simple. The latter relies on the IP binding of animation images and film and television works. Opened the cross-industry chain and turned passive ticket sales into active souvenir consumption. The sales of various IP derivatives in theme parks accounted for half of Disney's tourism revenue and also achieved the great cause of Disney's "Dream Empire."

Of course, there are also many major tourist countries that follow the example of the US Disney. Take Singapore and Thailand, the most frequent outbound destinations for Chinese, as an example. The water curtain fountain show at Sentosa in Singapore and the Dream Kingdom Theatre show in Phuket Fantasea Park, Thailand, although IP rights protection is very strong, The audience was strictly forbidden to take photos and videos, and the security check before the show was very strict. However, due to the excessive mix of folk songs, dances, acrobatics, magic, and comedies, the viewing process is too informative and the viewing process is more constrained, resulting in its inability to form a native "Disney Kingdom". The fundamental problem is still tourism Lack of cultural image. Whether it is a domestic tourism performance or a tourism performance in a neighbouring country in Southeast Asia, while studying the Disneyland theme park in the United States, the essence of its deployment "experience economy" is to provide links to people's history and emotions. Spatial places in tourist destinations are "not just functional, but emotional and influential." [3]Cartoons or animation are not exclusive to children, but a coup to break generations and find cultural identity. In order to paint the IP image, Disney's animators can stay in the National Forest Park for investigation, which is enough to see its rebellion against the "cultural industry" standardization and homogenization of goods. "Everyone can dream" is the essence of the American dream. The national cultural confidence conveyed by Disney may be the foundation for maintaining sustained innovation in tourism performing arts, shaping a unique ecological world, and building a global corporate environment.

\section{GAZING OF CARNIVAL: NEGLECTED PAN-ART CREATION}

Domestic tourism performing arts study often appear simply in the research reports of the tourism, environment or economic management industry, and are neglected and obscured in various studies of artistic creation. This shows that although the tourism performing arts industry is growing at a faster rate, and even the box office has increased faster than Chinese movies, its artistic quality, at least at the moment, may be the 7 th and 8 th arts research excluded. The comprehensive use of tourism performances in various major art categories and the integration of cross-media science and technology, its systematicity, complexity, and even artistry have actually exceeded the niche influence of traditional theatre narrative art or single exhibitions and interactive installations. Especially with the landscape and liberated body walking during the tour, the multidimensional sensory experience is threedimensional and profound to the public. The famous assertion by German artist Joseph Beuys that "everyone is an artist" has caused contemporary art to be pulled down from the altar. The tendency of pan-art creation makes life and art impossible to separate.

We might compare the traditional performing arts to song and dance, theatre, film and television, online video so on and so forth. Most of the previous art forms are just auditory and perplexing visual experience modes. The viewing ceremony is also a single "frame" or "Sit still" style, and the 
tourism performing arts, regardless of the on-site performances, live performances, or theme park performances mentioned above, can be relatively free to provide "seeing, hearing, touching, and flavouring" because of the complexity and diversity of the tourist landscape. "Smell, smell" the sense of unity, in several small theatres in the Disney theme park, "emergency raindrops, scent from the face, dolls from the sky" and so on are excellent examples. For another example, Xi'an, Shaanxi, has become a tourist 'Internet celebrity' due to its heavy history and extraordinary ancient capital temperament, and it has also taken the lead in the country in terms of tourism performances. Xi'an's two well-known travel performances, "The Past of Famen" and "The Legend of Camel Bell", the former created "on the move" viewing and immersive performances that made many young rockers feel: this is even cooler than standing and watching the music festival! The 360-degree surround stage and real animal performances realized by the latter will unfold folk customs, traditions, history, allusions, folk tales and other landscapes through moving landscapes. The audience seems to be in the picture scroll, and finds the duality of history and self in the instant performance coordinate.

People's bodies are no longer passive places, or "a sensory-practical action factor that shapes culture and produces culture." Tourists are both consumers and creators of culture. In the process of tourism spatial displacement, if conscious crossborder cooperation and pan-artistic creation are performed, the physical landscape and media of the destination are reproduced, and the created virtual landscape constitutes the unique "gazing carnival" of modern tourism. Considering the abovementioned tourism performing arts in terms of panartistic creation, its cultural value function is mainly reflected in the following aspects:

\subsection{Providing Psychological Compensation}

While tourism performing arts create virtual landscapes such as theme parks and film and television cities, the innovation of viewing behaviour also extends from static to dynamic, and one-dimensional acceptance becomes an interactive immersive experience while walking. Tourism performing arts display body-to-spiral "massage" for the trips due to boat and car fatigue and toil. With the continuous reform of the performance mode of tourism performances, geological culture, folk traditions, multi-ethnic customs and other sensory memories such as sight, hearing, taste, touch, and olfactory of the body accompanying tourism are generated at the same time. For local audiences to find identity, build cultural selfconfidence, and for foreign tourists to promote their understanding of Chinese culture, do more. An increasing number of inter-provincial or interregional tourism performance audiences is a progressive phenomenon. People don't watch the show because they have arrived at the attraction, but they look forward to seeing the show more because of the show.

\subsection{Completing Social Ceremony}

The essence of travel performance is show, drama, "super-real" "memory" and "land of imagination" proposed by Jean Baudrillard. With the implosion of information and the flat world brought by the Internet global village, people often cannot distinguish between imagination and reality. In the face of globalized urbanization, more and more "migratory birds" live, the identity anxiety of "empty nest" old people and new urban migrants, the cultural gap between generations, and perhaps in family tourism, parent-child tourism and their common viewing in the process of tourism performance, identity can be found, barriers can be broken, and cultural identity can be completed. Some people say that music, film and television are also social media that promote circle interaction, but the audience for travel performances is larger, wider and more diverse. People who are willing to go out of their familiar home to see the world, have a more active purpose of socializing, and find "distant similarity" may be much larger than the occasional spirits in the movie barrage or the online community.

\subsection{Promoting Media Integration}

Marshall McLuhan claims that "media is information", and because of its interdisciplinary and cross-media properties, tourism performing arts have very complicated requirements for the audiovisual presentation and sensory experience of works. It is not a simple synthesis of stage art and acoustic and optical technology, nor is it a song and dance reproduction or opera interpretation of the physical landscape. It is not just satisfied with smearing fireworks in landscape painting scrolls to attract people's attention. The performing arts of tourism are the survival of people today. Way to build a "flowing culture." The pan-artistic nature of tourism performing arts has played an excellent role 
in promoting the study of media fusion and cognitive communication in the senses of hearing, hearing, touch, taste and smell. Its on-site and immediate drama-like features are very obvious. At the same time, the pursuit of interactive performing arts by tourism performing arts, the mixing of virtual and real senses, and the coexistence of rational thinking and emotional memory may make traditional audiovisual media, even virtual reality and augmented reality. Video shows faded. People's panic about artificial intelligence and alienation of consumers by consumerism may be re-examined with the healthy development of tourism performing arts.

\section{CONCLUSION}

In summary, technological progress has made people see the value of emotions. Robots may help humans complete more than $70 \%$ of their work, but human passion and deep inner world is another infinite universe that is as vast as the solar system and worth exploring. The dramatic appeal of real life is the daily poetic resistance of people in modern society to resist suffering. The walking landscape is not only the body on the road, but also the concepts gained during the journey and the experience of burning into memory. Broadway's dramatic, colourful, mysterious and highly anticipated, more than $80 \%$ of the audience come from outside New York or overseas visitors. Why can a show last for decades? Why is it still difficult to get a ticket for the stage? If tourism performing arts combine social rituals, cultural symbols, ideology, and pan-artistic creation, it will have a huge and far-reaching impact on regional consumption, production, and even the national economy.

John Urry also put forward the concept of "cultural economy"[4] after the theory of "tourist gaze", that is, cultural capital increases the valuation and quantity of capital.[5] However, culture is largely taken for granted, with Hawaiian tourists spending on entertainment and cultural attractions as an example. "Estimations of the economic impact of Hawaiian museums and cultural attractions indicate that their contribution far exceeds expectations, at 340 million US dollars. However, this represents only 3\% of Hawaii's \$ 12 billion tourism industry, or only $0.7 \%$ of the country's total output value. " [6] As mentioned in this article, the current pan-artistic nature of domestic tourism performing arts is underestimated and its value underestimated. Li Ao, a Taiwanese famous writer, once advocated the "anti-tourism theory" and believed that the imagination obtained by reading poetry books and traveling around the world of literature was more important than walking around the mountains and headless flies. He has not left Taiwan for decades, and has no chance to set foot on the great rivers and mountains of the motherland. His ideas have been subject to great skepticism, and now reading the "anti-tourism theory" from the perspective of pan-artistic creation, his perception of culture is even more tickling. Tourism does not necessarily bring positive benefits, and the current status of tourism performing arts has many problems. But after all, "a thousand people have a thousand Hamlets." The abstract nature of literature and the interdisciplinary trend of tourism need more communication today than multi-culturalism. They need to be open and inclusive rather than dwell on the ground. Due to the trans-regional nature of audiences and diversified knowledge backgrounds, tourism performing arts can further promote artistic creation to break the boundaries of knowledge. Eventually, "from home to home", we greet guests from all directions as masters. This is exactly what the tourism performing arts are pursuing: telling Chinese stories with an international perspective, expressing artistic aesthetics with continuous innovation, and ultimately promoting selfconfidence in national culture.

\section{AUTHORS' CONTRIBUTIONS}

Shu $\mathrm{Li}$ is responsible for paper structure design and draft writing. Hao Liu analyzes data, and contributed to the revising.

\section{REFERENCES}

[1] In the past year, the box office of China's tourism and performing arts industry has increased by $20 \%$, surpassing that of films, [EB/OL], 2018-10-16[2019-1-20], http://www.sohu.com/a/259749095_99921450

[2] JUANITA C.LIU. Tourism and the value of culture in regions. The Annals of Regional Science[J]. (2005)39: 1-9

[3] JILLIAN M, RICKLY-BOYD, DANIEL C.KNUDSEN, LISA C.BRAVERMAN, MICHELLE M, METRO-ROLAND. Tourism, Performance and Place: A Geographic Perspective(New Directions in 
Tourism Analysis[M].UK: Ashgate Publishing Limited, 2014

[4] MC KEAN. P.F, Towards a theoretical analysis of tourism: Economic dualism and cultural involution in Bali[J]. In: SMITH VL eds. Hosts and guests: The anthropology of tourism[M]. Philadelphia: University of Pennsylvania Press ,1997

[5] URRY J. The tourist gaze: leisure and travel in contemporary societies[M], 2nd (ed). London: Sage Publications, 2002

[6] LIU J. Economic impact of Hawaii museums and their role in tourism[J]. Honolulu: Hawaii Museums Association, 1997 